\title{
Moving Towards Healthy Diets: The Key Role of Food Environments
}

\author{
Dalia Mattioni and Gianluca Brunori* \\ Department of Agriculture, Food, and Environment, University of Pisa, Italy
}

Submission:March 23, 2018; Published: April 13, 2018

*Corresponding author: Brunori G, Department of Agriculture, Food, and Environment, University of Pisa, Italy, Email: gbrunori2007@gmail.com

Keywords : Healthy diets; Micronutrient; Deficiencies; Overweight; Obesity; Chronic respiratory; Diabetes; Nutrition transition; Reshaping food

Abbreviations : TFCs: Transnational Food Corporations; LMICs: Low and Medium Income Countries

\section{Introduction}

Most countries today, in spite of the progress made in the last decade, face the "triple burden" of malnutrition: under nutrition, micronutrient deficiencies and overweight and obesity [1,2]. Progress in terms of reduction of stunting has been slow and uneven, while overweight and obesity in particular have grown rapidly contributing in part to the increase of non-communicable diseases such as cardiovascular diseases, cancers, chronic respiratory diseases and diabetes. According to the WHO, these have become the world's "biggest killers" with much of the burden of premature deaths from NCDs lying on the shoulders of low- and middle-income countries [3]. Today, about 2 billion adults are either overweight or obese, and no country has been able to reverse the rising trend [1].

One of the underlying causes of this rise, in addition to a reduced physical activity, has been a shift in dietary patterns worldwide. No doubt, the rise of income in certain parts of the world, notably China and some countries of Latin America, has led to a greater demand for and consumption of nutritious foods such fruits, vegetables, whole grains and seafood. On the other hand though, recent data tells us that there has also been a parallel - and faster- increase in the consumption of highly processed foods, such as sugar-sweetened beverages and processed meat [4]. Known as the "nutrition transition", diets have shifted worldwide towards a greater consumption of packaged, processed foods high in salt, refined carbohydrates and sugar, animal products and food cooked with vegetable oils to the detriment of coarse grains, root crops, legumes and fresh fruits and vegetables [5].

There is today a broad consensus on the key role played by the evolution of the food system in contributing to this shift. Urbanization, the changing lifestyle it has led to, and the overall increase in income, especially in middle-income countries, have certainly played a role in shaping a new demand: urbanization brings an increasing demand for meals away from home as commuting distances increase and working hours become long and at times unpredictable [6,7]. The last decades have also seen an increasing number of women enter the workforce, thus making ready-to-eat and ready-to-heat foods more attractive and convenient. However a number of recent reports from international agencies and academia clearly spell out the strong link between high-quality diets and the food system we have inherited from the post-world war II era [8-13].

Food environments in particular have been pointed out as an important mediating factor between what the food system delivers and the types of diets -healthy or not - that people have. There is to date no one agreed upon definition of food environments, but overall we can say that food environments are the underlying determinants of what people eat, and are made up of the foods that are available, affordable and acceptable to people in their surroundings $[10-11,14]$. In the short term they affect people's food choices, while in the long run they have an important role to play in affecting people's food preferences and habits [15].

Some global trends in the way food systems have evolved in the last 50 years have strongly affected food environments in the world. With respect to availability, shifts in the global supply system, especially with the rise of transnational food corporations (TFCs) have made energy-dense, nutrient-poor processed food products much more available. Moreover, technological advances in food processing, such as the extraction of vegetable oils and other processing techniques, 
have made the production of this type of food possible, profitable and less expensive for the consumers $[16,17]$.

The above changes have also had an impact on the relative prices of foods. Modern global sourcing strategies by food companies allows the use of cheap ingredients, thus making it possible to cut costs and keep prices - especially of highly processed packaged foods - low $[18,19]$. The result has been that, overall in the past decades, "healthy" foods such as fresh fruits and vegetables have become more expensive than "unhealthy" foods, both in high-income countries and in emerging economies, such as Mexico, Brazil and China [20]. However, it is important to note that in countries where traditional food systems are still important, fresh foods that are distributed by small, local producers tend to be cheap and therefore accessible [19]. A careful analysis of the retail structure, the type of food sold, and its impact on prices is therefore important in analyzing its effect on diets, as well as more research on issues such as the metrics used (cost per calories versus cost per nutrient, for example), or on the effects of price changes on total diet rather than on the consumption of a specific product [21].

The concept of acceptability includes that of desirability and convenience, and the transformations noted above have shifted the acceptability of food towards unhealthier patterns. The way that certain ultra-processed foods are manufactured is engineered to make them tastier and more palatable, thus making it very difficult to "eat little of them" - as some would advocate $[17,22]$. Processed food and modern distribution systems are today "trendy", particularly in low and medium income countries (LMICs). Snacking and eating out have increased, and have proceeded in parallel with a certain level of destructuration of the traditional meal $[23,24]$, as well as with a progressive loss of knowledge: people, especially young people, are no longer knowledgeable about certain types of (usually traditional) foods, nor do they know how to cook/process them. Information has played a key role in this transformation: the vast amount of funds being spent by large companies on advertising and marketing (including the strategic use of shelf space) have all played an important role in shaping acceptability, with an increased use of quick-to-use ultra-processed foods $[18,25,26]$. Availability therefore has a direct influence on diets- as seen above- but it also has an indirect effect insofar as what is available - and also what is affordable - shapes people's food preferences [15]. The result is that, even if healthier options are available, people may not like the taste or as mentioned above, would not know how to cook the healthy foods

While problems of overweight and obesity have repeatedly been framed in terms of people's "personal responsibilities", what the above points to is the need to broaden the frame of the debate around diets and nutrition and recognize the role of environmental and structural drivers in shaping people's eating behaviours [12], implying a strong role for Government and policy intervention. Generally speaking there is today a global consensus on the core policy domains where action is needed to foster a healthier food environment. These include: nutrition labelling, food provisioning (i.e. food offered in specific settings, such as schools), fiscal measures, food reformulation, food promotion (advertising and marketing), food retailing, and trade $[10,14]$. Some policy frameworks such as the NOURISHING framework - also include behaviour change communication as a key complementary area of work.

Faced with growing rates of obesity, countries have indeed risen to the challenge and have implemented a series of polices within these domains, ranging from innovative labelling laws in Chile and Ecuador to taxes on "unhealthy" products in Mexico and Hungary, advertising restrictions in the UK and zoning of fast foods especially around schools in the USA and South Korea, just to mention a few [27]. Many of these policy interventions are relatively new, but some are already showing some positive impacts on consumption. They include: relatively large and well signalled taxes, comprehensive advertising regulations on multiple media, and labelling policies, albeit the latter have a greater impact on stimulating reformulation than actually modifying substantially consumer choice [28,29] Evidence also suggests that integrating food environment policy actions with information and nutrition education campaigns enhances the overall effectiveness of the policy package [21], as does adopting an "integrated policy strategy", i.e. a mix of consistent and coherent food environment policies $[30,31]$.

More will be needed however to rise up to the task of reshaping food environments and, ultimately, food systems, and while great political commitment is required from Governments, greater public support for policy action will be needed by civil society and a range of actors [12-13,32]. "Policy" indeed is not to be considered as an exclusive domain of Government: civil society and the private sector too can forge policy from their respective quarters [33]. In a number of countries, evidence has shown that food-based, locallevel initiatives, such as community-supported agriculture, farmers' markets and box delivery schemes can encourage a shift in food practices [34-37]. Translated in governance terms, what this means is a need to "further support, fund and link these movements, coalitions and networks together if change is to come about" [13], and to set up platforms that encourage greater stakeholder participation in the construction of integrated food policies [12]. The task ahead in shifting eating patterns and dietary intake is huge: demanding greater political commitment and action by Governments as well as opening spaces of deliberation for the process to be participatory will be key. 


\section{References}

1. IFPRI (2016) Global Nutrition Report, Washington DC, USA.

2. FAO (2016) The future of food and agriculture trends and challenges, Rome, Italy.

3. WHO (2013) Global Action Plan for the Prevention and Control of Noncommunicable Diseases: 2013-2020, Geneva, Switzerland.

4. Inamura F, Micha R, Kathibzadeh S, Fahimi S, Powels J, et al. (2015) Dietary quality among men and women in 187 countries in 1990 and 2010: a systematic assessment, The Lancet 3(3): e132-e142.

5. Hawkes C, Popkin B (2015) Can the SDGs reduce the burden of nutritionrelated non-communicable diseases without truly addressing major food system reforms? BMC Medicine 13: 143.

6. Timmer P (2014) Managing Structural Transformation: a political economy approach, UNU-WIDER, Annual Lecture 18.

7. Pingali P (2015) Agricultural policy and nutrition outcomes - getting beyond the preoccupation with staple grains. Food Security7(3): 583591.

8. Swinburn B, Sacks G, Hall K, McPherson K, Finegood D, et al. (2011) The global obesity pandemic: shaped by global drivers and local environments. The Lancet 378(9793): 804-814.

9. Popkin B (2014) Nutrition agriculture and the global food system in low and middle income countries. Food Policy 47: 91-96.

10. IFPRI (2015) Global Nutrition Report, Washington DC, USA.

11. Global Panel on Agriculture and Food Systems for Nutrition (GLOPAN) (2016) How can Agriculture and Food System Policies improve Nutrition? Technical Brief, London, UK.

12. IPES-Food (2017) Unravelling the Food-Health Nexus: Addressing practices, political economy, and power relations to build healthier food systems. The Global Alliance for the Future of Food and IPES-Food.

13. HLPE (2017) Nutrition and food systems. A report by The High Level Panel of Experts on Food Security and Nutrition of the Committee of World Food Security, Rome, Italy.

14. Swinburn B, Sacks G, Vandevijvere S, Kumanyika S, Lobstein T, et al (2013) INFORMAS (International Network for Food and Obesity/noncommunicable diseases Research, Monitoring and Action Support): overview and key principles. Obes Rev 14(suppl 2): 1-12.

15. Hawkes C, Smith T, Jewell J, Wardle J, Hammond R, et al. (2015) Smart policies for obesity prevention. The Lancet 385(9985): 2410-2421.

16. Popkin B, Adair L, Ng S (2011) Global nutrition transition and the pandemic of obesity in developing countries. Nutr Rev 70(1): 3-21.

17. Monteiro C, Moubarac J, Cannon G, Ng S, Popkin B (2013) Ultraprocessed products are becoming dominant in the global food system. Obesity Reviews 14(suppl 2): 21-28.

18. Hawkes C, Chopra M, Friel S (2009) Globalization, trade and the nutrition transition. R Labonte, et al. (Eds.), In: Globalization and Health: Pathways, Evidence and Policy, New York: Routledge, USA, pp. 235-262.

19. Gomez M, Ricketts K (2013) Food value chain transformations in developing countries: selected hypotheses on nutritional implications. Food Policy 42: 139-150.

20. ODI (Overseas Development Institute) (2015) The rising cost of a healthy diet, London, UK.
21. Mozaffarian D, Afshin A, Benowitz N, Bittner V, Daniels S, et al. (2012) Population approaches to improve diet, physical activity, and smoking habits: a scientific statement from the American Heart Association. Circulation 126(12): 1514-1563.

22. Slimani N, Deharveng G, Southgate D, Biessy C, Chaje V, et al. (2009) Contribution of highly industrially processed foods to the nutrient intakes and patterns of middle-aged populations in the European Prospective Investigation into Cancer and Nutrition study. Eur J Clin Nutr 63(Suppl 4): S206-S225.

23. Mestdag I (2005) Disappearance of the traditional meal: temporal, social and spatial destructuration. Appetite 45(1): 62-74.

24. Yates L, Warde A (2015) The evolving content of meals in Great Britain. Results of a survey in 2012 in comparison with the 1950s. Appetite 84(1): 299-308.

25. Bereuter D, Glickman D (2015) Healthy Food For a Healthy World: Leveraging Agriculture and Food to Improve Global Nutrition, The Chicago Council on Global Affairs, Chicago, USA.

26. Cameron A, Thornton L, McNaughton SA, Crawford D (2012) Variation in supermarket exposure to energy-dense snack foods by socioeocnomic position. Public Health Nutr 16(7): 1178-1185.

27. Lee M, Popkin B, Kim S (2002) The unique aspects of the nutrition transition in South Korea: the retention of healthful elements in their traditional diet Public Health Nutr 5(1A): 197-203.

28. WHO (2015) Using price policies to promote healthier diets, Copenhagen, Denmark.

29. Mazzocchi M (2017) Ex-post evidence on the effectiveness of policies targeted at promoting healthier diets, FAO Trade Policy Technical Notes, No. 19 (November).

30. Howlett M, Rayner J (2007) Design Principles for Policy Mixes: Cohesion and Coherence in 'New Governance Arrangements. Policy and Society 26(4): 1-18.

31. UN Standing Committee on Nutrition (UNSCN) (2016), Impact Assessment of Policies to Support Healthy Food Environments and Healthy Diets, Discussion Paper, Rome, Italy.

32. Huang T, Cawley J, Ashe M, Costa S, Frerichs L, et al. (2015) Mobilisation of public support for policy actions to prevent obesity. The Lancet 385(9985): 2422-2431.

33. Lang T, Barling D, Caraher M (2009) Food Policy. Oxford, UK.

34. Brunori G, Rossi A, Guidi F (2012) On the new social relations around and beyond food. Analysing consumers' role and action in Gruppi di Acquisto Solidali (Solidarity Purchasing Groups). Sociologia Ruralis 52(1): 1-30

35. Cohen N, Ilieva R (2015) Transitioning the food system: A strategic practice management approach for cities. Environmental Innovation and Societal Transitions 17: 199-217.

36. Pitts S, Wu Q, Demarest CL, Dixon CE, Dortche CJ, et al. (2015) Farmers' market shopping and dietary behaviours among Supplemental Nutrition Assistance Program participants. Public Health Nutr Vol 18(13): 2407-2414

37. Minaker L, Olstad D, Thompson M, Raine K, Fisher P, et al. (2016) Associations between frequency of food shopping at different store types and diet and weight outcomes: Findings from the NEWPATH study. Public Health Nutr 19(12): 2268-2277. 


\section{Your next submission with Juniper Publishers} will reach you the below assets

- Quality Editorial service

- Swift Peer Review

- Reprints availability

- E-prints Service

- Manuscript Podcast for convenient understanding

- Global attainment for your research

- Manuscript accessibility in different formats

( Pdf, E-pub, Full Text, Audio)

- Unceasing customer service

Track the below URL for one-step submission https://juniperpublishers.com/online-submission.php 